\title{
Refractive Indices of Fused Silica at Low Temperatures*
}

\author{
R. M. Waxler and G. W. Cleek \\ Institute for Materials Research, National Bureau of Standards, Washington, D.C. 20234
}

(April 7, 1971)

\begin{abstract}
The refractive indices of a commercial fused silica specimen were determined at ten wavelengths from 404.7 to $667.8 \mathrm{~nm}$ over the temperature range from -200 to $+20{ }^{\circ} \mathrm{C}$. The data are needed for the design of optical systems for space applications where the extremes of temperature are encountered. Values of the thermal coefficient of refractive index were found to be positive and varied from about $9 \times 10^{-6} /{ }^{\circ} \mathrm{C}$ at room temperature to $3 \times 10^{-6} /{ }^{\circ} \mathrm{C}$ at liquid nitrogen temperature. The data also showed that there is an increase in dispersion with increasing temperature. These results bear out the predictions of the theory for the thermo-optic behavior of solids.
\end{abstract}

Key words: Fused silica; glasses; interferometry; optics; refractive index.

\section{Introduction}

Data on the refractive indices of fused silica at low temperatures are needed in the design of optical systems for space applications. A survey of the literature shows that Rinne $[1,2]^{1}$ made measurements to $-160{ }^{\circ} \mathrm{C}$ for four spectral lines of helium radiation. He used the classic minimum deviation method with a prism of fused silica and a goniometer which read to 2 s. The data are reported to 5 significant figures. Austin and Pierce [3] have reported on refractive indices to $-200{ }^{\circ} \mathrm{C}$ for one spectral line of helium at $587.6 \mathrm{~nm}$. These authors used an optical interference method in which change in optical path length was measured, and the change in refractive index from an initial value was calculated; the technique requires data on linear thermal expansion. This method makes it possible to obtain index data to 6 significant figures.

The source of the fused silica was not specified in either of the above investigations. In the present study, it was desired to obtain data on commerical fused silica, Corning Code $7940,{ }^{2}$ from +20 to $-200{ }^{\circ} \mathrm{C}$ for 10 wavelengths from 404.7 to $667.8 \mathrm{~nm}$.

Fused silica is an interesting material for study, because it is known from earlier work that the change of refractive index with temperature, $d n / d T$, is very large, being about $9 \times 10^{-6} /{ }^{\circ} \mathrm{C}$ at room temperature, [3] whereas for most optical crown glasses it is about 2 or $3 \times 10^{-6} /{ }^{\circ} \mathrm{C}[4,5]$. On the other hand, the coefficient of thermal expansion is extremely low, being about $0.5 \times 10^{-6} /{ }^{\circ} \mathrm{C}[6,7]$ while most optical glasses have

*This work was sponsored by Langley Research Center, NASA. National Aeronautics and Space Administration, W ashington, D.C. 20546.

${ }^{1}$ The figures in brackets indicate literature references at the end of this paper.

${ }^{2}$ Commercial materials are identified in this paper to specify the particular substance on which the data were obtained. In no instance does such identification imply recommendation or endorsement by the National Bureau of Standards or that the material identified is necessarily the best for the purpose. values on the order of 8 to $10 \times 10^{-6} /{ }^{\circ} \mathrm{C}[4]$. There is, therefore, a large value of $d n / d T$ for fused silica which cannot be attributed to change in volume.

\section{Experimental Method}

The interference method employed by Austin and Pierce [3] offers the attractive feature of high precision of measurement. There is the additional feature that, since the specimen employed is small, thermal gradients constitute less of a problem. Moreover, a continuous record of change in optical path length may be obtained by using a continuously recording camera. For these several reasons it was decided to use this basic method with some amplifications to permit the photographing of fringe shifts for several spectral lines simultaneously.

In the optical interference method the specimen in the form of a plate with flat, polished faces constitutes the interferometer. When this plate is viewed in reflection using collimated, monochromatic light, a pattern of localized, Fizeau-type interference fringes may be seen at the top surface. For a specimen of thickness, $t$, and refractive index, $n$, the fringe number $N$ is given by

$$
N \lambda=2 t n .
$$

A change in temperature, $T$, will cause a shift in the fringe pattern, because of changes in $t$ and $n$. By differentiating (1) and rearranging it is found that

$$
\frac{\Delta n}{\Delta T}=\frac{\Delta N \lambda}{2 t \Delta T}-\frac{n \Delta t}{t \Delta T} .
$$

For a given temperature interval, $\Delta T$, a measurement of the number of fringes that pass a fixed reference 
mark and the change in thickness, together with data on the initial index and thickness, permit the calculation of $\Delta n$.

The shift in interference fringes was recorded photographically on high speed film, using an optical system similar to the one described by Saunders [8]. It has been found that the proper adjustment of a prism in Saunders' apparatus permits the recording of fringe shifts for several spectral lines on the same film [9]. In the present investigation four spectral lines of helium, 471.3, 501.6, 587.6 and $667.8 \mathrm{~nm}$ were recorded on one film, four spectral lines of cadmium, 467.8, $480.0,508.6$, and $643.8 \mathrm{~nm}$ were recorded on a second and two lines of mercury, 404.7 and $435.8 \mathrm{~nm}$ were recorded on a third.

The fused silica specimen was about $0.3 \mathrm{~cm}$ in thickness. This specimen was half-silvered on the front surface and fully silvered on the back surface in order to increase the brightness in the image plane.

The specimen was enclosed in a cryostat, in which liquid nitrogen was used to effect the reduction in temperature; this apparatus has been described [10]. In the present experiment, liquid nitrogen was added, a little at a time, and, after each addition, a waiting period of about one-half hour was allowed for a quasiequilibrium condition to obtain. The temperature was measured at each plateau with a potentiometer and a calibrated copper-constantan thermocouple. Calculations showed that the sensitivity of measurement was $0.02{ }^{\circ} \mathrm{C}$ at room temperature and $0.5{ }^{\circ} \mathrm{C}$ at the lowest temperatures. In each run, eight to twelve temperature intervals provided data points from +20 to about $-192^{\circ} \mathrm{C}$.

\section{Results and Discussion}

The experiments involved only measurement of changes in optical path, and initial values of refractive index at $20^{\circ} \mathrm{C}$ for the various spectral lines were those reported by Malitson [11]. The small corrections for the change in length, $\Delta t$, were taken from the data of Scheel and Heuse [6] which are recommended by Sosman in his compendium on silica [7]. With this information plus the measured values of $\Delta N$, it was possible to calculate $\Delta n$ for each temperature interval. It was estimated that shifts could be measured to one-tenth of an interference fringe, and calculations showed that this meant that the sensitivity of measurement was about $\pm 2 \times 10^{-5}$ in $\Delta n$.

The calculated values of $\Delta n$ were then fitted by computer to a cubic equation, and values of $\Delta n$ at temperature intervals of $10{ }^{\circ} \mathrm{C}$ were printed out from +20 to $-200{ }^{\circ} \mathrm{C}$. These increments were added to the initial values of refractive index, and the results which refer to air at $20^{\circ} \mathrm{C}$ are shown in table 1 . The standard deviation of each value of the original data was within $\pm 1 \times 10^{-5}$.

The initial values of refractive index used in the present study differed from those of the earlier investigators, but it is still possible to make a comparison of the changes in refractive index between two specified temperatures. The temperatures, 18 and $-160{ }^{\circ} \mathrm{C}$ were selected because Rinne $[1,2]$ reports his data at these points, and Austin and Pierce [3] give an equation from which these values may be obtained. In the present study, values at $18{ }^{\circ} \mathrm{C}$ were found from the computer run although they are not given in table 1 .

TABLE 1. Refractive index of fused silica, Corning Code 7940, as a function of temperature and wavelength

\begin{tabular}{|c|c|c|c|c|c|c|c|c|c|c|}
\hline & $\begin{array}{c}667.8 \\
\mathrm{He}\end{array}$ & $\begin{array}{c}643.8 \\
\mathrm{Cd}\end{array}$ & $\begin{array}{c}587.6 \\
\mathrm{He}\end{array}$ & $\begin{array}{c}508.6 \\
\text { Cd }\end{array}$ & $\begin{array}{c}501.6 \\
\mathrm{He}\end{array}$ & $\begin{array}{c}480.0 \\
\text { Cd }\end{array}$ & $\begin{array}{c}471.3 \\
\mathrm{He}\end{array}$ & $\begin{array}{c}467.8 \\
\mathrm{Cd}\end{array}$ & $\begin{array}{c}435.8 \\
\mathrm{Hg}\end{array}$ & $\begin{array}{c}404.7 \\
\mathrm{Hg}\end{array}$ \\
\hline+20 & 1.45607 & 1.45670 & 1.45846 & 1.46186 & 1.46224 & 1.46350 & 1.46406 & 1.46429 & 1.46669 & 1.46962 \\
\hline+10 & 1.45599 & 1.45663 & 1.45838 & 1.46177 & 1.46215 & 1.46431 & 1.46398 & 1.46420 & 1.46661 & 1.46953 \\
\hline 0 & 1.45590 & 1.45655 & 1.45829 & 1.46169 & 1.46206 & 1.46332 & 1.46389 & 1.46412 & 1.46653 & 1.46944 \\
\hline-10 & 1.45582 & 1.45647 & 1.45821 & 1.46161 & 1.46198 & 1.46323 & 1.46381 & 1.46403 & 1.46645 & 1.46935 \\
\hline-20 & 1.45573 & 1.45639 & 1.45813 & 1.46152 & 1.46189 & 1.46315 & 1.46372 & 1.46395 & 1.46637 & 1.46926 \\
\hline-30 & 1.45565 & 1.45631 & 1.45805 & 1.46144 & 1.46181 & 1.46306 & 1.46364 & 1.46386 & 1.46629 & 1.46918 \\
\hline-40 & 1.45557 & 1.45623 & 1.45797 & 1.46136 & 1.46173 & 1.46298 & 1.46356 & 1.46378 & 1.46620 & 1.46909 \\
\hline-50 & 1.45550 & 1.45615 & 1.45789 & 1.46128 & 1.46165 & 1.46290 & 1.46347 & 1.46370 & 1.46612 & 1.46901 \\
\hline-60 & 1.45542 & 1.45607 & 1.45781 & 1.46120 & 1.46157 & 1.46282 & 1.46340 & 1.46362 & 1.46604 & 1.46892 \\
\hline-70 & 1.45535 & 1.45600 & 1.45774 & 1.46112 & 1.46150 & 1.46275 & 1.46332 & 1.46354 & 1.46597 & 1.46884 \\
\hline-80 & 1.45528 & 1.45592 & 1.45767 & 1.46105 & 1.46143 & 1.46267 & 1.46324 & 1.46347 & 1.46589 & 1.46876 \\
\hline-90 & 1.45521 & 1.45585 & 1.45760 & 1.46098 & 1.46136 & 1.46260 & 1.46317 & 1.46340 & 1.46581 & 1.46869 \\
\hline-100 & 1.45514 & 1.45578 & 1.45753 & 1.46091 & 1.46129 & 1.46254 & 1.46310 & 1.46333 & 1.46574 & 1.46862 \\
\hline-110 & 1.45508 & 1.45571 & 1.45747 & 1.46085 & 1.46123 & 1.46247 & 1.46304 & 1.46326 & 1.46567 & 1.46855 \\
\hline-120 & 1.45503 & 1.45565 & 1.45741 & 1.46079 & 1.46116 & 1.46241 & 1.46297 & 1.46320 & 1.46561 & 1.46848 \\
\hline-130 & 1.45497 & 1.45560 & 1.45736 & 1.46073 & 1.46111 & 236 & 1.46291 & 1.46314 & 1.46555 & 1.46842 \\
\hline-140 & 1.45492 & 1.45554 & 1.45731 & 1.46068 & 105 & 231 & 1.46286 & 1.46309 & 1.46549 & 1.46837 \\
\hline-150 & 1.45488 & 1.45550 & 1.45726 & 1.46063 & 100 & 1.46226 & 1.46281 & 1.46304 & 1.46544 & 1.46832 \\
\hline-160 & 1.45484 & 1. 5546 & 1.45722 & 059 & 1.46095 & $1: 46222$ & 1.46276 & 1.46300 & 1.46539 & 1.46828 \\
\hline-170 & 1.45480 & 543 & 719 & 055 & 091 & 218 & 1.46272 & 1.46297 & 1.46535 & 1.46824 \\
\hline-180 & 1.45477 & 1.45541 & 1.45716 & 1.4 & 087 & 1.46215 & 1.46269 & 1.46294 & 1.46531 & 1.46821 \\
\hline-190 & 475 & 540 & 713 & 049 & 084 & 1.46212 & 1.46266 & 1.46291 & 1.46528 & 1.46818 \\
\hline-200 & 1.45473 & 1.45539 & 1.45711 & 1.46047 & 1.46081 & 1.46210 & 1.46264 & 1.46289 & 1.46525 & 1.46816 \\
\hline
\end{tabular}


TABLE 2. Change in refractive index, $-\Delta \mathrm{n} \times 10^{4}$, for fused silica for the temperature interval from +18 to $-160^{\circ} \mathrm{C}$

\begin{tabular}{|c|c|c|c|c|}
\hline$\lambda, \mathrm{nm}$ & 667.8 & 587.6 & 501.6 & 4.71 .3 \\
\hline $\begin{array}{l}\text { Present study... } \\
\text { Austin and Pier }\end{array}$ & 12.1 & \multirow{2}{*}{$\begin{array}{l}12.2 \\
11.8 \\
11\end{array}$} & 12.7 & 12.8 \\
\hline 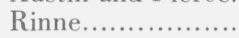 & 10 & & 12 & 14 \\
\hline
\end{tabular}

The differences in refractive index are shown in table 2 for the four wavelengths used by Rinne and the single wavelength employed by Austin and Pierce. Considering that the sensitivity of measurement of the interference method is $\pm 2 \times 10^{-5}$, the difference of $4 \times 10^{-5}$ for the two values of $\Delta n$ at $587.6 \mathrm{~nm}$ (data of Austin and Pierce versus data of the present study) seems reasonable. Rinne's data are of lesser precision, but, recognizing this, the agreement between the sets of data appears to be good.

It should be noted that the data obtained here bear out the phenomenological theory for the thermal change in the refractive index of solids which has been developed by Ramachandran [12, 5, 13]. According to this theory, $d n / d T$ in a solid depends upon (1) a change in the number of dispersion centers and (2) a variation in the dispersion frequencies. This variation in the dispersion frequencies, in turn, shows a dependence upon volume change as the solid expands as well as an effect due purely to temperature.

From data on commercial glasses [5] and fused silica [13], Ramachandran has inferred that the variation of the dispersion frequencies in these materials is essentially independent of change in volume and is almost solely dependent on temperature change itself. This is very apparent in the case of vitreous silica where the thermal expansion is extremely small, and the shift in the fundamental dispersion frequency accounts almost entirely for the observed changes in $d n / d T$. Values of $d n / d T$ for the spectral line of $587.6 \mathrm{~nm}$ are shown as a function of temperature in figure 1. It can be seen in the figure that $d n / d T$ decreases continuously to the lowest temperatures investigated, even though there is a maximum in the density of fused silica at about $-80^{\circ} \mathrm{C}[6,7]$.

The theory also predicts that the magnitude of the temperature shift of the fundamental absorption band decreases with fall of temperature, and probably vanishes at low temperatures. In fused silica this is manifested in the variation of $d n / d T$ with temperature as shown in figure 1. For several commercial optical glasses, Molby [4] has found that refractive index versus temperature data exhibit a minimum at some reduced temperature. The commercial glasses have an appreciable thermal expansion (in contrast to fused

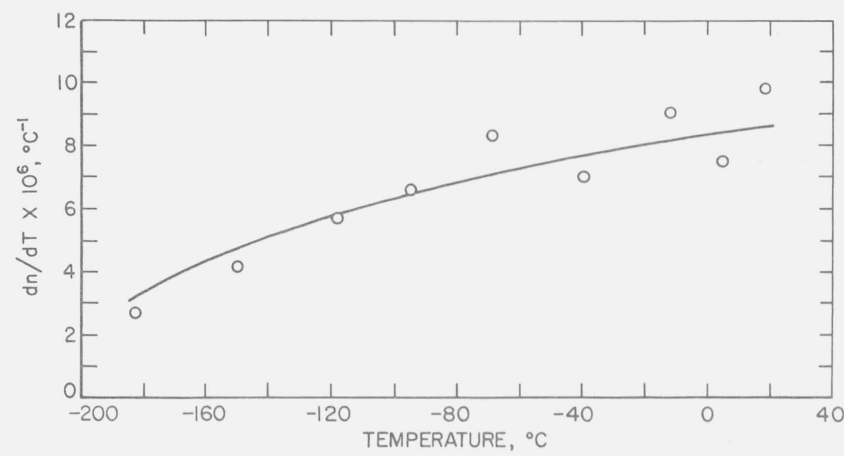

Figure 1. Temperature variation of $\mathrm{dn} / \mathrm{dT}$ for fused silica at the helium spectral line of $587.6 \mathrm{~nm}$.

The curve represents smoothed data taken from the computer run. The points represent values of $\Delta n / \Delta T$ calculated from the experimental data between two adjacent values of temperature and plotted at the mid-point.

silica) with an accompanying contribution to $d n / d T$ that is always negative because of the lessening in the number of dispersion centers. The data on the optical glasses may be explained by the reduced contribution to $d n / d T$ by the temperature shift of the fundamental absorption band at low temperatures.

Ramachandran has pointed out that the shift of fundamental absorption band with increasing temperature is toward longer wavelengths, so that there is an increase in dispersion. This is borne out by the data for fused silica shown in table 1 , by subtracting the value of the refractive index for the spectral line of $667.8 \mathrm{~nm}$ from that at $404.7 \mathrm{~nm}$, comparison shows that the differences are 0.01343 and 0.01355 at -200 and $+20^{\circ} \mathrm{C}$, respectively.

\section{References}

[1] Rinne, F., Nues Jahrb. Mineral, Beil. 39, 388 (1914).

[2] Sosman, R. B., The Properties of Silica, (Chemical Catalog Company, New York, 1927) p. 687.

[3] Austin, J. B., and Pierce, R. H. H., Jr., Physics 6, 43 (1935),

[4] Molby, F. A., J. Opt. Soc. Am. 39, 600 (1949).

[5] Ramachandran, G. N., Proc. Indian Acad. Sci. 25A, 498 (1947).

[6] Scheel, K., and Heuse, W., Verh. Deutsch. Physik, GES. 16:1-3.

[7] Sosman, R. B., The Properties of Silica, (Chemical Catalog Co., New York, 1927) pp. 403-406.

[8] Saunders, J. B., J. Res. Nat. Bur. Stand. (U.S.) 35, 157-186 (1945) RP 1668.

[9] Waxler, R. M., Weir, C. E., and Schamp, H. W., Jr., J. Res. Nat. Bur. Stand. (U.S.), 68A (Phys. and Chem.) No. 5, 489498 (Sept.-Oct. 1964).

[10] Wachtman, J. B., Jr., Scuderi, T. G., and Cleek, G. W., J. Amer. Ceram. Soc. 45, 319 (1962).

[11] Malitson, I. H., J. Opt. Soc. Am. 55 No. 10, 1205 (1965).

[12] Krishnan, R. S., Progress in Crystal Physics, Volume I, (Interscience Publishers, New York, London, 1958) pp. 139-167.

[13] Ramachandran, G. N., Proc. Indian Acad. Sci. 25A, 280 (1947).

(Paper 75A4-669) 